$\begin{array}{ll} & \text { Etnográfica } \\ \text { etnográfica } & \text { Revista do Centro em Rede de Investigação em }\end{array}$

Antropologia

vol. 11 (1) | 2007

Vol. 11 (1)

\title{
Usos da ruralidade: apresentação
}

João Leal

\section{(Q) OpenEdition \\ Journals}

\section{Edição electrónica}

URL: https://journals.openedition.org/etnografica/1874

DOI: 10.4000/etnografica. 1874

ISSN: 2182-2891

\section{Editora}

Centro em Rede de Investigação em Antropologia

\section{Edição impressa}

Data de publição: 1 maio 2007

Paginação: 57-62

ISBN: 0873-6561; E-ISBN 2182-2891

ISSN: 0873-6561

\section{Refêrencia eletrónica}

João Leal, «Usos da ruralidade: apresentação», Etnográfica [Online], vol. 11 (1) | 2007, posto online no dia 25 setembro 2012, consultado o 12 fevereiro 2022. URL: http://journals.openedition.org/ etnografica/1874 ; DOl: https://doi.org/10.4000/etnografica.1874

\section{(@) $(1) \Theta$}

Etnográfica is licensed under a Creative Commons Attribution-NonCommercial 4.0 International License. 


\title{
Usos da ruralidade: apresentação
}

\section{João Leal}

\author{
Departamento de Antropologia da FCSH (UNL) \\ e Centro de Estudos de Antropologia Social (ISCTE)
}

1. EM 1996 TEVE LUGAR NO MUSEU NACIONAL DE ETNOLOGIA (LISBOA) a exposição "O Voo do Arado". O título da exposição (e do catálogo que a secundou) visava chamar a atenção para as transformações profundas que o mundo rural português conheceu nas últimas décadas. Já então era de facto evidente que em Portugal, à semelhança de outros países europeus, se assistia a um processo de pós-ruralização, cujas marcas - económicas, sociais e culturais - eram cada vez mais claras.

Esse processo de pós-ruralização do país teve reflexos importantes na produção antropológica portuguesa das últimas décadas. Historicamente estruturada - entre 1870 e 1980 - em torno de uma orientação ruralista, a antropologia portuguesa viu-se de alguma forma empurrada para a necessidade de rever essa sua orientação preferencial. Nascia, assim, uma antropologia portuguesa pós-rural.

Uma das expressões dessa nova antropologia tem sido a multiplicação de novos objectos e de novos terrenos - situados resolutamente fora do universo da ruralidade - na reflexão antropológica sobre Portugal. Uma parte significativa da produção antropológica portuguesa - centrada em contextos urbanos, industriais, étnicos - passou assim a situar-se para além desse horizonte ruralista. Simultaneamente, desenvolveram-se novos modos de gestão da herança ruralista da antropologia portuguesa, estruturados em torno da investigação da ruralidade e da cultura popular, não já como objectos de estudo em si, mas como práticas discursivas construídas a partir desses objectos. Isso traduziuse, em primeiro lugar, na afirmação de uma direcção de trabalho orientada para o exame dos discursos historicamente produzidos, quer no âmbito da antropologia portuguesa ruralista quer no âmbito de outras áreas - geografia 
humana, artes, literatura - que ao longo de um período de mais de um século tematizaram o popular e o rural. E traduziu-se, em segundo lugar, no desenvolvimento de uma linha de trabalho atenta ao modo como a ruralidade e a cultura popular continuam a configurar, no novo contexto de pós-ruralização do país, recursos importantes para a construção de discursos vários sobre tradição e raízes que têm vindo a povoar a paisagem cultural e ideológica portuguesa contemporânea. Alguns desses discursos têm por protagonistas agentes sociais ligadas às novas comunidades pós-rurais. Outros desenvolvem-se nos contextos da diáspora portuguesa, recente ou longínqua. Outros, ainda, atravessam campos tão heterogéneos como as artes plásticas e a criação musical ou as políticas estatais para o mundo rural.

2. Os artigos reunidos no dossiê que a seguir se publica inserem-se nestas duas linhas de trabalho e são, nessa medida, um contributo para a consolidação e o alargamento deste campo de estudos pós-rural.

A primeira direcção de trabalho está representada através dos artigos de Vera Marques Alves, José Neves e Sónia Vespeira de Almeida, que abordam um conjunto de construções discursivas sobre a ruralidade, situadas no arco temporal longo que vai dos anos 1940 ao imediato pós 25 de Abril.

$\mathrm{O}$ artigo de Vera Marques Alves debruça-se sobre os discursos e práticas etnográficas desenvolvidas durante o Estado Novo pelo SPN/SNI. O tema em si não é novo, mas a perspectiva desenvolvida pela autora introduz um conjunto de elementos até agora insuficientemente explorados. Assim, no plano dos conteúdos discursivos, Vera Marques Alves, para além de revisitar a estreita associação entre a cultura popular e os discursos de identidade nacional, dá especial ênfase à particular concepção de cultura popular subjacente à "política de espírito” de António Ferro. De facto, no seguimento de uma orientação que começa por se desenhar na etnografia dos anos da I República, a cultura popular é, para o Estado Novo, sinónimo de arte popular: os seus camponeses são sobretudo "camponeses estetas": "produtor[es] de peças de arte encantadoras, ele[s] próprio[s] transformado[s] em figura[s] de adorno e em objecto[s] de contemplação". Mas é sobretudo na tocante à caracterização das audiências das acções do SPN/SNI centradas na cultura popular que a contribuição de Vera Marques Alves surge como mais inovadora. A este respeito, a autora resgata, por um lado, a importante dimensão internacional das iniciativas do SPN/SNI. E sublinha, por outro lado, o modo como, internamente, é junto das classes médias que se desenvolve uma parte significativa da actividade do SPN/SNI. A importância destes dois pontos deve ser sublinhada: como a autora mostra, eles colocam-nos perante a importância dos mecanismos de reconhecimento e competição internacional e de nacionalização das classes médias na construção das identidades nacionais na Europa do século XX.

Quanto ao artigo de José Neves, debruça-se sobre o lugar da cultura popular e da ruralidade na produção literária de Alves Redol, uma das figuras cimeiras 
do neo-realismo português. Alargando o estudo das formas de tematização do popular para a produção literária, o artigo de José Neves confronta-nos sobretudo com o universo das "etnografias espontâneas" produzidas à esquerda no decurso do Estado Novo. Este ponto - ao qual voltaremos - deve ser enfatizado. Longe de ser um recurso mobilizado exclusivamente pelo poder estadonovista, a cultura popular e a ruralidade foram também intensamente tematizadas - de modo alternativo - pela esquerda, no quadro de uma guerra cultural em que estavam em discussão diferentes modos de definição da cultura popular e das suas virtualidades. No seu argumento, José Neves está particularmente atento às formas específicas desta construção da ruralidade à esquerda em Alves Redol. Nela avultam, entre outros, dois motivos. De um lado, um fascínio pelo mundo rural - especialmente claro na monografia Glória do Ribatejo - marcado em larga medida pelo mito do comunismo primitivo. Do outro, a tentativa - particularmente evidente no romance Gaibéus e no conto A Vida Mágica da Sementinha - de pôr esse mundo em diálogo com uma concepção da história marcada pelo "elogio obeirista da modernidade industrial, que era apanágio do sovietismo russo". Por intermédio destes e doutros motivos é uma imagem alternativa do povo - onde a ruralidade dialoga com alguns grandes tópicos do pensamento comunista - que Alves Redol propõe.

É também de imagens alternativas do povo que fala o artigo de Sónia Vespeira de Almeida sobre as Campanhas de Dinamização Cultural e Acção Cívica desenvolvidas pelo Movimento das Forças Armadas (MFA) no imediato pós-25 de Abril. Orientadas para o contacto directo e para o esclarecimento político-cultural das populações, as campanhas privilegiam uma concepção de povo que, deixando de fora o operariado industrial e agrícola, o faz coincidir com o Portugal dos campos e das aldeias, da agricultura familiar, assente numa clara dicotomia entre o Sul - já politicamente consciente - e o Norte - "onde haveria que despertar os camponeses para a sua vocação revolucionária". Privilegiando esta "ruralidade a norte", as campanhas discursá-la-ão, entretanto, de modo paradoxal. Assim, o povo rural do Norte é visto, por um lado - na linha, por exemplo, do discurso contra-pastoral que marca em plano de relevo o Inquérito à Habitação Rural (1943-1947) - como um povo "atrasado", "miserável”, um povo condenado pelo fascismo ao subdesenvolvimento. Mas, ao lado desta "narrativa negativa, que se organiza em torno do nexo camponeses - fascismo", desenvolve-se uma outra, construída em torno de uma visão romântico-revolucionária da cultura popular, que procede ao "elogio da ruralidade num tom de valorização das culturas locais concebidas como 'a expressão autêntica de um povo". Estas, reprimidas pelo Estado Novo, seriam o terreno a partir do qual os camponeses se poderiam constituir em sujeitos históricos da revolução.

3. Os artigos de Luís Silva e Sandra Xavier colocam-nos, na linha da segunda grande direcção de trabalho que comecei por pôr em evidência, perante alguns usos contemporâneos da ruralidade como universo ideológico. 
O artigo de Luís Silva aborda os processos de patrimonialização e turistificação dos campos que são uma das expressões principais da pós-ruralização do país. Centrada no turismo em espaço rural (TER), a sua contribuição está sobretudo interessada nas motivações que conduzem os turistas - maioritariamente citadinos da classe média - a procurarem este tipo de turismo. Entre essas motivações, como o autor defende, ocupam lugar de particular relevo imagens culturalmente construídas da ruralidade. Animados por uma sensibilidade pastoral, os frequentadores do TER vêem o campo como um lugar "autêntico", onde é possível fugir à artificialidade e ao stress da vida citadina. Essa autenticidade é pensada em vários registos. Mas há dois ou três que me parecem particularmente relevantes. Por um lado, ela é pensada num registo que tem a ver com os modos de sociabilidade: o campo seria um espaço de relações sociais mais genuínas, que seriam ilustradas pelas próprias relações personalizadas que, no quadro do TER, se estabelecem entre hóspedes e hospedeiros. Por outro lado, essa autenticidade é vista como algo que permitiria o re-encontro com o país autêntico, uma espécie de mergulho revigorador no "Portugal profundo". Finalmente, essa autenticidade é pensada no próprio registo da identidade pessoal: como sublinha Luís Silva, "a frequentação dos campos por parte dos citadinos proporciona a oportunidade para [estes] recuperarem a sua própria autenticidade".

$\mathrm{O}$ artigo de Sandra Xavier, finalmente, transporta-nos para os encontros com a ruralidade da arquitectura paisagista portuguesa contemporânea. Centrado num dos mais destacados arquitectos paisagistas portugueses - João Gomes da Silva -, o seu artigo navega em águas próximas da contribuição de Luís Silva. De facto, o projecto sobre o qual o artigo se debruça é um projecto implantado numa herdade alentejana, tendo em vista conjugar o uso agrícola actual do território com o seu futuro uso (eco)turístico. Partindo deste estudo de caso, Sandra Xavier mostra como a arquitectura paisagista de Gomes da Silva reserva uma lugar de particular destaque a tipologias rurais, vistas, mais uma vez - neste caso por intermédio do conceito de genius loci-, como mais autênticas. A autora começa por estabelecer uma genealogia intelectual das ideias de Gomes da Silva. Nestas, para além da influência de arquitectos paisagistas como Caldeira Cabral e Ribeiro Telles, avultam as lições do Inquérito à Arquitectura Popular Portuguesa e dos arquitectos - como Álvaro Siza - interessados no diálogo entre tipologias eruditas e tipologias populares e, por fim, as tematizações da cultura popular da antropologia portuguesa dos anos 1950 e 1960. Mas, através do recurso ao conceito de objectificação da cultura, está sobretudo interessada em mostrar os processos de "selecção, descontextualização e reinterpretação" que presidem à transformação das tipologias rurais em critério para a construção de paisagens destinadas à fruição estética e lúdica.

4. Encarados no seu conjunto, os artigos publicados neste dossiê são um contributo relevante para uma cartografia mais diversificada dos discursos, 
históricos e contemporâneos, produzidos a partir da ruralidade e da cultura popular.

Essa cartografia reforça linhas de interpretação já adquiridas, relacionadas, por exemplo, com a importância das práticas discursivas sobre a ruralidade na paisagem cultural, ideológica e política do país ou com a multiplicidade de protagonistas envolvidos nessas práticas discursivas. Simultaneamente, sublinha a pertinência do desenvolvimento de linhas de reflexão ainda insuficientemente estruturadas.

Uma delas tem a ver com a possibilidade e a necessidade de uma caracterização mais exacta deste campo discursivo. A acumulação de estudos começa de facto a possibilitar (e até a exigir) que se comece a pensar nalgumas grandes constantes que parecem reger o seu modo de funcionamento. Este parece assentar num conjunto diverso mas limitado de tropos que mantêm entre si uma relação sistemática, feita de recorrências, de oposições e de transformações. No quadro deste dossiê, é por exemplo flagrante a lógica contrastiva que separa os discursos do Estado Novo dos discursos à esquerda - como os de Alves Redol ou do MFA - sobre a cultura popular. Mas essa guerra cultural não disfarça o modo como Estado Novo e MFA pensam - cada um à sua maneira - o povo como um lugar de criatividade cultural mais genuína. De igual modo não deixam de surpreender as similitudes entre a tematização "comunista" do povo em Alves Redol e o modo como os frequentadores do TER vêem o campo como um lugar de relações sociais mais autênticas. Se incluirmos na comparação a tematização do comunitarismo agro-pastoril de Jorge Dias, torna-se inevitável constatar a persistência deste tropo, bem como as suas transformações. As similitudes entre os modos de tematização da ruralidade na arquitectura paisagista e na antropologia portuguesa dos anos 1950 e 1960 - que poderiam ser alargadas a disciplinas como a geografia humana - devem também ser sublinhadas. Verificar até que ponto e de que modo estes - e outros - jogos de diferenças e similitudes obedecem a padrões dotados de alguma consistência parece pois ser uma das direcções de trabalho que este dossiê - somando-se a muitos outros estudos anteriores - ajuda a tornar mais clara.

Outra linha de reflexão prende-se com o exame dos agentes sociais envolvidos nos discursos sobre cultura popular e ruralidade. Durante muito tempo, a investigação nesta área privilegiou os discursos produzidos pela inteligentzia. A maior parte dos artigos publicados neste dossiê sugere entretanto a pertinência da consideração mais atenta de outros agentes sociais. Entre eles, deve ser sublinhada a importância do Estado e das políticas estatais, tratada nos artigos de Vera Marques Alves, de Sónia Vespeira de Almeida e de Luís Silva. $\mathrm{Na}$ mesma linha deve ser também enfatizado o modo como tanto o artigo de Vera Marques Alves como o artigo de Luís Silva sublinham o envolvimento das classes médias - na qualidade de destinatárias e consumidoras - nos discursos construídos a partir da ruralidade. Em ambos os casos, de formas diferentes, 
somos confrontados com a necessidade de combinar produção, circulação e consumo/apropriação na análise dos discursos sobre o popular. Presente noutros estudos - que têm privilegiado, por exemplo, desdobramentos locais deste campo discursivo - esta direcção de trabalho é vital, se quisermos perceber e caracterizar melhor a importância social deste tipo de representações e o modo como elas desenham de forma efectiva as paisagens culturais e ideológicas que continuamos a habitar. 